\title{
Socialt arbete i Malmö: Perspektiv och utmaningar
}

\section{CARIN BJÖRNGREN CUADRA, PHILIP LALANDER \& ERICA RIGHARD}

\begin{abstract}
Vid Institutionen för socialt arbete på Malmö högskola samlas stora delar av forskningen under en gemensam programförklaring om social utsatthet. Vi beskriver här några teoretiska och normativa utgångspunkter, centrala forskningsområden och den relation vi försöker bygga upp med forskningsfältet. Vi ger även konkreta exempel på vår forskning.
\end{abstract}

Med begreppet social utsatthet riktar vi fokus mot orättvisor och processer som gör att individer och grupper hamnar $i$ sårbara livssituationer som kan innebära att deras framtidsmöjligheter, deras möjligheter att fä en någorlunda trygg livssituation, och deras hälsa och upplevelse av värdighet hotas. Social utsatthet betraktas i plattformen som nagot processuellt och något som skapas och utvecklas beroende på hur man är positionerad $i$ den lokala, nationella, välfärdsstatliga och globala kontexten. I analyser av social utsatthet är det viktigt att synliggöra människors aktörskap. Men det är också

Carin Björngren Cuadra, docent.

Philip Lalander, professor.

Erica Righard FD, Institutionen för socialt arbete, Malmö högskola. av stor vikt att inte se aktörskapet frikopplat frain kontextuella faktorer.

Så inleder vi vår text ${ }^{1}$ om den forskningsplattform med namnet Social utsatthet och socialt arbete (SUSA) som ett trettiotal forskare och lärare vid Institutionen för socialt arbete enats om. Två huvudfrågor är centrala för vårt arbete:

- Hur kan man förstå och förklara de processer som skapar och motverkar social utsatthet?

- Hur kan socialt arbete organiseras,

1 Denna text finns att läsa i sin helhet på http:// www.mah.se/susa, klicka först på Om plattformen (i vänstermarginalen) och sedan på Plattformförklaring (under LÄS MER). 
bedrivas och utvecklas för att motverka och minska social utsatthet?

Frågorna är inte särskilt originella men de svarar upp mot de utmaningar som socialt arbete står inför, både som akademisk disciplin och verksamhetsområde. Lokala och globala processer förändrar ständigt förutsättningarna för socialt arbete. Vår forskning och utbildning bygger på och stimulerar till ett kritiskt förhållningssätt till dessa processer och de utmaningar de innebär. I våra kollegiala diskussioner har vi speciellt tagit fasta på ekonomisering, individualisering och globalisering - tre övergripande och ofta sammanlänkade processer. I det följande skisseras vad vi menar med dessa.

Ekonomiseringen av det sociala och det politiska innebär att ett marknadstänkande blir en organiserande, överordnad och självklar princip, ett slags naturlig ordning (Clarke 2007; Brown 2003). Detta har konsekvenser för socialt arbete. Marknadsanpassningen har inneburit en privatisering och outsourcing av olika sociala funktioner, såsom exempelvis behandlingshem, äldreboenden, skolor och hem för flyktingar. Den utgör även en grogrund för olika former av socialt företagande. Denna anpassning har breddat vägen för etableringen av New Public Management (NPM) inom det sociala området, en marknadsanpassning av verksamheter och sociala interventioner som har långtgående verkningar för det sociala arbetets villkor (Clarke \& Newman 1997).

Individualisering utgör både en förutsättning för och en konsekvens av den starka ekonomiseringen. För den enskilde handlar det om att göra individuella val, att se över sig själv och sin identitet i relation till de konsumtionsobjekt, -drömmar och -behov som ständigt skapas i den ekonomiska ackumulationen (Beck \& BeckGernsheim 2002; Bauman 2002). Sociala strukturer tillskrevs en stor betydelse för att förstå social utsatthet under välfärdsstatens expansion, i synnerhet i samband med den radikalisering av det sociala och politiska som skedde mot slutet 1960-talet. Idag ligger stark fokus på individen när det gäller såväl att förstå och förklara olika former av sociala problem. Att sätta diagnoser i centrum och att betona människans biologi, psykologiska och neuropsykiatriska status har blivit en dominerande trend de senaste decennierna och innebär en medikalisering och biologisering av sociala problem (Bourgois \& Schonberg 2009).

Slutligen har vi tagit fasta på globalisering vilken involverar ekonomiska, politiska, kulturella och demografiska dimensioner. Medan globaliseringen av ekonomin länge var i ensamt fokus, framträder idag den tilltagande internationella migrationen som en av globaliseringens mest genomgripande uttrycksformer (Castles \& Miller 2009). Under det senaste halvseklet har internationell migration ökat väsentligt i omfattning, men också ändrat karaktär (Faist 2000). Sociala nätverk grundade i den teknologiska utvecklingen underlättar och förstärker kontaktytor mellan människor och platser i olika delar av världen. Globalisering är på så sätt en process i människors nära relationer och vardag. Dess influenser i människors vardag och i hur sociala stödstrukturer och sociala problem tar sig uttryck, har konsekvenser för socialt

Björngren Cuadra, Lalander \& Righard: Socialt arbete i Malmö: Perspektiv och utmaningar. 
arbete, både som vetenskaplig disciplin och verksamhetsområde.

Det "sociala" är inte nödvändigtvis avgränsat till ett lokalt eller nationellt sammanhang, utan blir ibland begripligt först när det förstås i sitt trans-lokala sammanhang. Trans-lokala sammanhang kan inbegripa geografiskt skilda platser i ett, två eller flera länder (Brickell \& Datta 2011). Detta betyder att administrativa avgränsade system som kommunen eller nationalstaten, som ofta organiserar det sociala arbetets praktik, inte nödvändigtvis svarar upp mot människors vardagsliv och den dynamik som skapar och motverkar social utsatthet i dagens samhälle. Globaliseringen innebär att relationer, situationer och fenomen på platser "långt borta" har relevans för vår förståelse av sociala stödstrukturer, social utsatthet och socialt arbete "här", i det lokala sammanhanget. Det nationellt inramade välfärdspolitiska systemet och dess underliggande värderingar utmanas på så sätt av den internationella migrationen.

De övergripande processer vi förhåller oss till är inflätade i varandra och avspeglas i forskningsplattformens frågor. Processerna är i viss mening både lokala, nationella och globala, dvs. de skapas och fortplantas genom globala flöden och kommunikationssystem och de påverkar och bidrar till att utforma förutsättningar för det lokala livet.

\section{Skilda världar}

De senare decennierna har vi kunnat bevittna en utveckling som inneburit ökade sociala klyftor i samhället. Skillnaderna ökar mellan länder, inom länder och $\mathrm{i}$ städer. Det handlar bland annat om skillnader gällande hälsa, utbildning, boende, sysselsättning och inkomster. I många städer sammanfaller de sociala och ekonomiska skillnaderna med olika geografiska områden i staden. I Malmö är denna uppdelning så framträdande att man ibland till och med talar om att staden glider isär - om det "tudelade Malmö". Anlagda bränder och stenkastning i några av stadens mest socialt och ekonomiskt utsatta områden har kommit att spä på denna bild och retorik. Inom plattformen ser vi denna "tudelning" som komplex och flerdimensionell. Det handlar om hur sociala, ekonomiska och politiska relationer i växelverkan både skapar och skapas av den tudelade stadens alla delar (Dikeç 2001).

Inkomstskillnader är väsentliga för att förstå fattigdomens dynamik i världens mer välmående länder. I Sverige har dessa skillnader vuxit sedan tidigt 1980-tal och i Malmö är de idag omfattande. I Malmö ligger den disponibla inkomsten klart under genomsnittet i Sverige, och inkomstgapet är större. Detta innebär att de rikaste tio procenten av Malmös befolkning har en genomsnittligt lägre disponibel inkomst än de tio rikaste procenten i riket, men framförallt så innebär det att de fattigaste tio procenten har en disponibel inkomst som är mycket lägre än de tio fattigaste procenten i riket. Faktum är att i Malmö har de fattigaste blivit fattigare $i$ absoluta mått mätt (Salonen 2012). Detta är exceptionellt och mycket nedslående.

Förståelsen av människors utsatthet och ojämlikhet handlar om att se till sociala 
strukturer, sociala relationer och aktörskap, hur över- och underordning reproduceras $\mathrm{i}$ olika situationer och processer. Även media spelar en roll i reproduktionen av ojämlikhet genom stereotypa och problemtyngda beskrivningar av vissa grupper i befolkningen och områden i staden. Detta gäller inte minst i Malmö (Hallin m.fl. 2010).

Det går inte att förstå dessa processer enbart i sitt lokala rum där de kommer till uttryck, utan det är viktigt att studera hur de är sammankopplade med det nationella, transnationella och globala, dvs. i den nya världens "glokala" arkitektur (Listerborn 2012). Det etablerade samhället, välfärdsstatliga institutioner och socialt arbete som praktikområde kan här verka marginaliserande och exkluderande i det att det bygger på normer och värderingar som inte har någon samklang med de identiteter och villkor under vilka människor lever sin vardag. I plattformen närmar vi oss detta i ett antal studier där vi lägger oss nära de processer som sker i Malmö och dess omgivning. En studie fokuserar på hur vissa familjeformer framstår som "avvikande" utifrån en välfärdsstatlig diskursiv tolkning och samtidigt som rationella ur ett transnationellt perspektiv (Righard 2011). Doktorandprojektet Att växa upp i glokala rum sätter fokus på möjligheter och hinder att ta plats för unga kvinnor i socialt utsatta områden. Ett annat doktorandprojekt, Children - but not quite, studerar de ensamkommande flyktingbarnens position i den svenska välfärdsstaten. Ytterligare ett forskningsprojekt fokuserar på hur den svenska välfärdsmodellen utmanas av irreguljära migranters "papperslösas" - närvaro (Björngren Cuadra 2012; Björngren Cuadra \& Staaf 2012).

\section{Aktörskap och värdighet}

Frustration över ojämlikhet kan leda till att människor går samman i organiserade eller spontana nätverk för att utöva motstånd. Hur detta går till och kan förstås utgör ett centralt forskningsintresse i plattformen. Med anknytning till framförallt ungdomskulturforskning studeras hur nätverk representerar ett sökande efter tillhörighet, trygghet, mening och identitet (Lalander 2009; Johansson \& Lalander 2012). Dessa nätverk kan representera ett behov av en annan förståelse av den värld vi lever och navigerar $i$, en annan typ av kognitiv karta än den som etablerade representanter för samhället tillhandahåller (Lalander \& Sernhede 2011). Motstånd utövas i Malmö liksom på andra platser. Det kan vara spontant, löst organiserat och använda sig av andra kanaler och andra uttryckssätt än det etablerade politiska systemet.

Den stenkastning mot poliser som för några år sedan gjorde Rosengård till en nyhetsarena kan förmodligen förstås som spontant och löst organiserat. Liknande händelser utspelades i flera svenska städer, såsom Landskrona, Göteborg, Uppsala och Stockholm. Dessa aktioner ägde rum i områden präglade av arbetslöshet och låg status och det är inte svårt att se stenkastningen och andra aktiviteter som ett utslag för en stark frustration mot den sociala och ekonomiska ojämlikheten och mot avsaknaden av kanaler att göra sin röst hörd. I den meningen är stenkastningen ett uttryck för ett aktörskap och ett motstånd som har sin grund i frustrationer över olika typer av orättvisor som skapas i skärningspunkten mellan position i fråga om ålder, 
klass, kön och etnicitet och de sociala, kulturella och ekonomiska sammanhang människor lever i.

Vi menar att det är viktigt att synliggöra att formerna för ojämlikhet och motstånd är mångfasetterade och kan ses på en rad samhällsarenor. Arbetslivet är en sådan arena där villkoren ändrats väsentligt under senare decennier (Standing 2011). Inom plattformen studeras dessa ändrade villkor och dess betydelse för hur motstånd på arbetsplatsen tar sig uttryck (Mulinari 2012).

\section{Det sociala arbetets kärnområden}

Fattigdom, missbruk/beroende, barn/ unga/familj, åldrande/äldre och funktionsnedsättning utgör centrala områden i plattformen. Områdena är inte originella utan snarare högst etablerade inom det sociala arbetets verksamhetsfält. Vi menar att de också är av central betydelse för att vi ska kunna närma oss den sociala utsatthetens uttryck och komplexitet.

Den missbruksforskning som bedrivs inom plattformen analyserar konsekvenser av individualisering, medikalisering och ekonomisering för såväl den enskilde människan som för vårdsystemet och narkotikapolitiken (Svensson 2012; Johnson 2010). Ett doktorandprojekt inom detta område berör tungt narkotikamissbruk utifrån teman som injektionsmissbruk, vardagsliv, försörjningsstrategier, utsatthet, risktagande och heroinöverdoser. Ett annat doktorandprojekt heter Khat i Sverige och studerar användare och användning av khat i Sverige. Forskningen lägger stark tonvikt vid att förstå missbruk och missbruksvård relaterat till sociala, politiska, kulturella och ekonomiska strukturer på olika nivåer (Lalander 2009; Svensson 2007; Johnson 2007).

Forskningen inom området barn, ungdom och familj handlar till stora delar om att bättre förstå hur olika former av utsatthet skapas i ett samspel mellan globala och lokala rum och hur olika aktörer, såväl ungdomar och vuxna som representanter från organisationer och myndigheter försöker hantera den sociala utsatthet som skapas i staden. I detta sammanhang och i projektet Vad vet vi om vilka insatser socialtjänsten gör $i$ hedersrelaterade konflikter? studeras hur olika diskurser gör anspråk på att definiera olika former av våldsutövande. Hur våldutövandet kan förstås av våldsutsatta kvinnor studeras i doktorandprojektet Kvinnors förhållningssätt till polisanmälningar och medverkan i brottsutredningar. Där studeras hur våldsutsatta kvinnor upplever möten med myndigheter. Flera forskningsprojekt har en nära anknytning till verksamheter, till exempel forsknings- och behandlingsprojektet ALVHA som riktar sig mot familjer med späd- och småbarn där en eller båda föräldrarna lider av psykisk ohälsa.

Inom äldreområdet studeras bland annat konsekvenser av omstruktureringen av omsorgen såsom privatisering, skattesubventioner av hushållsnära tjänster (RUT) och ökad tyngdpunkt på valfrihet (LOV). Frågor som fokuseras är hur denna omstrukturering samverkar och sammanflätas med demografiska förändringar (åldrande befolkning) och ändrade migrations- 
flöden. Detta skapar nya förutsättningar för organiseringen och utövandet av äldreomsorgen (Magnusson \& Torres 2010) med nya mönster av över- och underordningar (Lill 2007; 2010). Pågående forskning adresserar nya förutsättningar för omsorgen av äldre och konsekvenser för arbetstagarna inom äldreomsorgen.

Inom området funktionshinder ligger en stark fokus på människors möjligheter till delaktighet. Ett studieområde utgörs av hur delaktighet formas i gränslandet mellan olika välfärdsinsatser, exempelvis insatser enligt antingen socialtjänstlagen (SoL) eller lagen om stöd och service till vissa funktionshindrade (LSS) (Larsson 2008, kommande 2013). Ett annat studieområde är möjlighet till delatighet $\mathrm{i}$ arbetslivet för personer med funktionsnedsättningar. I plattformen studeras detta i relation till det förändrade arbetslivet och samverkan mellan stödsystem (Germundsson \& Runesson kommande 2013). Ytterligare ett studieområde är relationen mellan hjälpmedel och delaktighet (Krantz 2012).

\section{Kunskapssyn}

I det att vi ser social utsatthet som något som skapas och utvecklas beroende på hur man är positionerad i den lokala, välfärdsstatliga och globala kontexten, så sätter vi fokus på sociala relationer och sociala strukturer. Detta har konsekvenser för vår förståelse både av det socialas kunskapsbas och det socialas räckvidd.

Socialt arbete utgör en del av det moderna projektet. Detta innebär att det sociala har likställts med det nationella, inte minst genom välfärdsstatens uppbyggnad. Genom att sätta fokus på det socialas räckvidd uppmärksammar vi hur denna avgränsning utmanas av globaliseringen. Plattformen intar en kritisk hållning till exkluderande processer som den nationella inramningen av "det sociala" innebär, både när det gäller att definiera vems behov och vems rättigheter som är legitima (Björngren Cuadra 2012; Righard 2009).

Det att vi sätter fokus på individualiseringen och ekonomiseringen av den sociala sfären har konsekvenser för hur vi förstår både social utsatthet och socialt arbete. Vi menar att social utsatthet måste förstås i det sociala sammanhang det uppstår. På detta sätt formulerar vi en kritik mot ekonomiseringen och understryker vikten av att vitalisera det "sociala" i socialt arbete och i social förändring. Detta innebär även en kritik mot en förment värdeneutral kunskapsbas i socialt arbete. Istället sätter vi fokus på socialt arbete som en normativ praktik (Herz 2012). Kunskapssyn i socialt arbete är på så sätt ett centralt tema i forskningsmiljön och även ett forskningsfält i sig självt (Righard \& Montesino 2012).

\section{Forskning för förändring}

En vägledande ambition i plattformen är att forskningen ska leda till social förändring. I den meningen företräder vi "aktörsparadigmet" inom socialt arbete (Brante 2003). Forskningen i plattformen är inriktad mot de processer som skapar och förstärker social utsatthet och de interventioner som genomförs för att motverka social utsatthet. Närheten till fältet stärks genom att 
involvera fler aktörer än de som finns inom det etablerade välfärdssystemet, men även genom att skapa mindre ortodoxa arenor för möten mellan forskare, praktiker, politiker, frivilligorganisationer, människor som på olika sätt har erfarenhet av social utsatthet och inte minst, studenter och doktorander. På dessa arenor möjliggörs en vidgning av synen på kunskapsobjektet i forskningen i socialt arbete. Vidgningen ligger $i$ att fler röster, även de som uppfattas som dissonanta, gör sig hörda.

Röster som på detta sätt har gjort sig hörda i plattformen är Kritiska organiserade socialarbetare (KAOSA) i Malmö. De är ett nätverk som sätter fokus på orättvisor och ojämlikhet, men även kritiserar vad som betraktas som självklara rutiner inom socialt arbete. Andra exempel på röster som hörs i plattformen är Bryta tystnaden och Asylgruppen. Dessa nätverk kritiserar de befinliga villkoren samtidigt som de vill åstadkomma förbättringar av mottagningssystemet. Nätverken utgör exempel på olika former av kritik och motstånd mot de villkor som skapar eller förstärker social utsatthet och försöker bidra till nya lösningar där "det sociala arbetet kan vara annorlunda". 2

Ett sista exempel på en icke-ortodox arena är nätverket Ett enat Malmö som initierades av plattformen våren 2012. Där ingår, förutom Institutionen för socialt arbete, representanter för Glokala folkhögskolan, Romskt informations- och kunskapscentrum, Malmö stad, Skåne stads-

2 Citat hämtat från KAOSA:s hemsida, http:// kritiskaorganiseradesocialarbetare.wordpress. com/ mission, Enter mötesplats, ungdomsorganisationen Helamalmö, Välkommen och Hassela helpline. Nätverket har som ambition att motverka social utsatthet och dess konsekvenser bland ungdomar i Malmö. I avsiktsförklaringen till Ett enat Malmö står följande:

Det finns olika berättelser om Malmö. En berättelse handlar om övergången från industrisamhället till kunskapsstaden med de nya infrastrukturerna; högskolan, bron, Västra hamnen. En annan berättelse handlar om fattigdom och den ökande segregationen. En återkommande berättelse handlar om kriminalitet. En berättelse som är osynlig $i$ den mediala rapporteringen om staden är det Malmö som sjuder av ett intensivt gräsrotsarbete och ett glödande engagemang, för att förbättra de sociala villkor och den utsatthet många människor lever i. Det finns en myriad av olika typer av verksamheter $i$ staden som präglas av ett sökande efter framgångsrika arbetssätt och modeller inom socialt arbete och med kopplingar till andra verksamhetsområden.

Ett enat Malmö utgör ett exempel på hur vi i plattformen arbetar tillsammans med olika aktörer. En aktivitet som vi är i full gång att planera är en sommarakademi som kommer att äga rum $i$ augusti $i$ år. Denna utformas tillsammans med aktörer i Ett enat Malmö och vänder sig till alla som är intresserade. Vår ambition är att nå unga och vuxna människor som annars inte söker sig till högskolekurser eller folkhögskolor och som är osäkra på vilka möjligheter de har. Sommarakademin är inte uppbyggd traditionellt akademiskt utan ska vara ett 
forum där olika kunskapsformer kan mötas och utvecklas. I de kunskapsflöden som uppstår i de mötesforum som diskuterats ovan skapas vidgade möjligheter för att formulera relevanta forskningsfrågor och att omsätta forskningen på fältet. Att göra så här tror vi kan skapa förändring. Forsk- ningsplattformen har därmed en dubbel ambition där, det å ena sidan handlar om att bidra till samhällsdebatt och kritiskt vetenskaplig diskussion, och å andra sidan tillsammans med andra aktörer bidra till social förändring.

\section{Litteratur}

Bauman, Zygmunt (2002) Det individualiserade samhället. Göteborg: Daidalos.

Beck, Ulrich \& Elisabeth Beck-Gernsheim (2002) Individualization. Institutionalized individualism and its social and political consequences. London: Sage.

Björngren Cuadra, Carin (2012) Irregular migrants challenging policy hierarchies and health professions. The case of Sweden. Journal of Hospital Administration, Årg. 1, Nr. 2, ss. 34-41.

Björngren Cuadra, Carin \& Annika Staaf (2012) Public social services' encounters with irregular migrants in Sweden. Amid values of social work and control of migration. European Journal of Social Work. Publicerad online 06 Dec 2012. DOI:10.1080/13691457.2012.739556

Bourgois, Philippe I. \& Jeff Schonberg (2009) Righteous dopefiend. Berkeley: University of California Press.

Brante, Thomas (2003) Konsolideringen av nya vetenskapliga fält. Exemplet forskning i socialt arbete I: Högskoleverket (Red.) Socialt arbete. En nationell genomlysning av ämnet Stockholm: Högskoleverkets rapportserie 2003: 16R.

Brickell, Katherine \& Ayona Datta (2011) Translocal geographies. Spaces, places, connections. Farnham: Ashgate.

Brown, Wendy (2003) Neo-liberalism and the end of liberal democracy. Theory \& Event, Årg. 7, Nr. 1, ss. 1-23.

Castles, Stephen \& Mark J. Miller (2009) The age of migration. International population movements in the modern world. Basingstoke: Palgrave Macmillan.

Clarke, John (2007) Subordinating the social? Cultural Studies, Årg. 21, Nr. 6, ss. 974-987.

Clarke, John \& Janet Newman (1997) The mana gerial state. Power, politics and ideology in the remaking of social welfare. London: Sage.

Dikeç, Mustafa (2001) Justice and the spatial imagination. Environment and Planning A, Årg. 33, Nr. 10, ss. 1785-1805.

Faist, Thomas (2000) The volume and dynamics of international migration. Oxford: Oxford University Press.

Germundsson, Per \& Ingrid Runesson (kommande 2013) Arbetsmarkanden för unga med funktionsnedsättning. I: Olofsson, Jonas (Red.) Ungas etablering-utmaning-och möjligheter. Stockholm: FAS.

Hallin, Per Olof, Alban Jashari, Carina Listerborn \& Margareta Popoola (2010) Det är inte stenarna som gör ont. Röster från Herrgården, Rosengård - om konflikter och erkännande. Malmö: Malmö Publikationer i Urbana Studier, MAPIUS 5, Malmö högskola.

Herz, Marcus (Red.) (2012) Kritiskt socialt arbete. Malmö: Liber.

Johansson, Thomas \& Philip Lalander (2012) Doing resistance youth and changing theories of resistance. Journal of Youth Studies, Årg. 15, Nr. 8, ss. 1078-1088.

Björngren Cuadra, Lalander \& Righard: Socialt arbete i Malmö: Perspektiv och utmaningar. 
Johnson, Björn (2007) After the Storm. Developments in Maintenance Treatment Policy and Practice in Sweden 1987-2006. I: Edman, Johan \& Kerstin Stenius (Red.) On the Margins. Nordic alcohol and drug treatment 1885-2007. Nordens välfärdscenter: Nordic Council for Alcohol and Drug Research (NAD), NAD publikation nr. 50.

Johnson, Björn (2010) Risker och sidoeffekter i läkemedelsassisterad behandling av opiatberoende. Socialvetenskaplig tidskrift, Årg. 17, Nr. 1, ss. 46-66.

Krantz, Oskar (2012) Assistive devices utilisation in activities of everyday life. A proposed framework of understanding a user perspective. Årg. 7, Nr. 3, ss. 189-198.

Lalander, Philip (2009) Respekt. Gatukultur, ny etnicitet och droger. Malmö: Liber.

Lalander, Philip \& Ove Sernhede (2011) Social mobilization or street crimes. Two strategies among young urban outcasts in contemporary Sweden. Educare, Årg. 7, Nr. 2, ss. 99-121.

Larsson, Monica (2008) Att förverkliga rättigheter genom personlig assistans. Lund: Lunds universitet, Socialhögskolan.

Larsson, Monica (kommande 2013) Social rights within the frame of personal assistance in a Swedish context. Opportunity for participation for people with disabilities? I: Matthies, Aila-Leena \& Lars Uggerhoej (Red.) Participation, marginalisation and welfare services in Europe. Aldershot: Ashgate Publishing.

Lill, Linda (2007) Att göra etnicitet. Inom äldreomsorgen. Malmö: Malmö högskola.

Lill, Linda (2010) Äldreomsorg. Om makt, genus, klass och känslor i ett yrke. Malmö: Liber.

Listerborn, Carina (2012) Suburban women and the 'glocalisation' of the everyday lives. Gender and glocalities in underprivileged areas in Sweden. Gender, Place \& Culture. Publicerad online 17 Jan 2012. DOI: 10.1080/0966369X.2011.649351

Magnússon, Finnur och Torres, Sandra (2010) Invandrarskap, äldrevård och omsorg. Malmö: Gleerups.

Mulinari, Paula (2012) Motstånd och fatalism. Läkares erfarenheter av rasism. Arbetsmarknad \& Arbetsliv, Årg. 18, Nr. 4, ss. 23-39.

Righard, Erica (2009) The family as a nation-state project in a global context. Implications for 'social citizenship' and social welfare. Zeit schrift für Sozialpädagogik (special issue: Transnationality and social work), Årg. 7, Nr. 4, ss. 373-390.

Righard, Erica (2011) Nära relationer och globalisering i vardagen. I: Salonen, Tapio (Red.) Hela staden. Social haillbarhet eller desintegration? Umeå: Boréa.

Righard, Erica \& Norma Montesino (2012) Conceptions of knowledge in Swedish social work education. A historical account. Social Work Education, Årg. 31, Nr. 5, ss. 651-662.

Salonen, Tapio (2012) Befolkningsrörelser, försörjningsvillkor och bostadssegregation. En sociodynamisk analys av Malmö. Malmö: Kommission för ett socialt hållbart Malmö.

Standing, Guy (2011) The Precariat. London: Bloomsbury Academic.

Svensson, Bengt (2007) Pundare, jonkare och andra. Med narkotikan som följeslagare. Stockholm: Carlsson.

Svensson, Bengt (2012) Narkotikapolitik och narkotikadebatt. Lund: Studentlitteratur. 